\section{PREVENTION OF BLEEDING AFTER CARDIOPULMONARY BYPASS WITH HIGH-DOSE TRANEXAMIC ACID}

\section{Double-blind, randomized clinical trial}

This prospective, double-blind, randomized trial assessed the effectiveness of high-dose tranexamic acid given in the preoperative period on blood loss in patients undergoing cardiopulmonary bypass. One hundred fifty patients scheduled to undergo cardiac operations with cardiopulmonary bypass were randomized into three groups of equal size. The first group received 10 gm of tranexamic acid intravenously over 20 minutes before sternotomy and a placebo infusion over 5 hours. The second group received $10 \mathrm{gm}$ of tranexamic acid over 20 minutes and then another $10 \mathrm{gm}$ infused intravenously over 5 hours. The control group received a placebo bolus and a placebo infusion over 5 hours ( $0.9 \%$ normal saline solution). The blood loss after the operation was measured at 6 hours and 24 hours. The homologous blood and blood products given during and up to 48 hours after operation were recorded. Eighteen percent of the control group patients shed more than $750 \mathrm{ml}$ blood in 6 hours compared with only $2 \%$ in both tranexamic acid groups. Patients who shed more than $750 \mathrm{ml}$ blood required $93 \%$ more red blood cell transfusions than patients without excessive bleeding. Tranexamic acid $(10 \mathrm{gm})$ given intravenously in the period before cardiopulmonary bypass reduced blood loss over 6 hours by $50 \%$ and over 24 hours by $35 \%$. Continued tranexamic acid infusion (10 gm over 5 hours) did not reduce bleeding further. There was no difference in the coagulation profile before operation between patients with and without excessive bleeding. However, coagulation tests done in the postoperative period indicated ongoing fibrinolysis and platelet dysfunction in patients with excessive bleeding. (J THORAC CARDIOvaSC SURG 1995;110:835-42)

Jacek M. Karski, MD, ${ }^{\text {a }}$ Sally J. Teasdale, MD, ${ }^{a}$ Peter Norman, MD, ${ }^{\text {a }}$ Jo Carroll, RN, Karl VanKessel, BSc, Peter Wong, BSc, and M. F. X. Glynn, MD, ${ }^{\mathrm{b} \dagger}$ Toronto, Ontario, Canada
Tras wenty percent of patients will bleed excessively after cardiac operations done with the use of cardiopulmonary bypass (CPB). Five percent of all patients having a cardiac operation will require immediate reoperation to control this excessive bleeding. ${ }^{1}$ In $50 \%$ of patients undergoing reopera-

From the Departments of Anesthesia ${ }^{a}$ and Hematology, ${ }^{b}$ The Toronto Hospital General Division, University of Toronto, Toronto, Canada.

Supported in part by the Heart and Stroke Foundation of Ontario, grant A2063, and Kabi-Pharmacia, Mississauga, Ontario, Canada.

Received for publication Jan. 27, 1995.

Accepted for publication Feb. 10, 1995.

Address for reprints: Jacek Karski, MD, Department of Anesthesia, The Toronto Hospital General Division, 200 Elizabeth St., Toronto, Ontario, Canada, M5G 2 C4.

${ }^{\dagger}$ Deceased.

Copyright 1995 by Mosby-Year Book, Inc.

$0022-5223 / 95 \$ 5.00+0 \quad \mathbf{1 2 / 1 / 6 4 1 6 2}$ tion a surgical cause of bleeding is found. All other patients with excessive bleeding will be found to have coagulopathy. Patients having coagulopathy in the postoperative period will often require massive transfusions of blood and blood products.

This postoperative coagulopathy results from an activation of fibrinolysis and platelet dysfunction commonly seen after $\mathrm{CPB} .^{2-6}$ With respect to fibrinolysis, its prevention by synthetic antifibrinolytic administration ( $\epsilon$-aminocaproic acid or tranexamic acid [TA]) to patients undergoing CPB has not always reduced bleeding. ${ }^{7}$ This is because the dosage and the timing of the use of antifibrinolytic drugs in cardiac operations have never been adequately established. With respect to blood platelets, structural and functional defects of the platelet receptors have been identified. ${ }^{8-10}$ Recently, it has been demonstrated that preservation of the platelet receptors in patients given aprotinin (Trasylol), an enzymatic inhibitor of fibrinolysis, correlates to a reduction of postoperative bleeding. ${ }^{8}$ 
In this institution, two antifibrinolytic agents, TA and $\epsilon$-aminocaproic acid, are routinely used prophylactically to prevent post-CPB bleeding. TA and $\epsilon$-aminocaproic acid exert their antifibrinolytic effect through the formation of a reversible complex with a modified plasminogen. ${ }^{11,12}$ TA also competitively inhibits the activation of enteropeptidase and noncompetitively inhibits its proteolytic activity. In addition, it has a weak effect on thrombin and an even weaker inhibitive effect on plasmin. ${ }^{13-15}$ The elimination half-life of TA has been reported to be 80 minutes ${ }^{14}$ and about $90 \%$ of the dose is recovered from the urine after 24 hours. ${ }^{16}$ Direct comparison of potencies indicates that TA is 6 to 10 times more potent than $\epsilon$-aminocaproic acid and sustains a greater antifibrinolytic activity in rat tissue. ${ }^{17}$

Clearly, therapy designed to preserve the structure and function of the patient's own circulating platelets would be preferred over the transfusion of homologous platelets. This suggests that if therapy designed to prevent damage to platelets is to be successful, the therapy should be given before the platelets are injured by the trauma of CPB. ${ }^{9,16,18-23}$

A review of our retrospective data published elsewhere ${ }^{23}$ has led us to conclude that TA given intravenously in a dosage of $10 \mathrm{gm}$ (but not $6 \mathrm{gm}$ ) during the 1 hour before sternotomy would completely prevent excessive bleeding after $\mathrm{CPB}(>750$ $\mathrm{ml}$ in the first 6 hours after CPB). This therapy has also resulted in a reduction in the number of patients receiving blood products. The effectiveness of TA in a dosage of $10 \mathrm{gm}$ or greater in the reduction of post-CPB bleeding has not been studied in a prospective manner.

This prospective study was therefore designed to examine two problems. First, we studied the effect of pretreatment with TA before cardiac surgery on postoperative blood loss and the effectiveness of TA to eliminate excessive bleeding in patients. Second, we examined whether it is possible to predict from preoperative tests of the coagulation systems which patients will have excessive bleeding after operation. To answer these questions, we examined blood loss in the post-CPB period after a bolus dose of TA 10 gm or a placebo was administered before sternotomy followed by either an infusion of TA $10 \mathrm{gm}$ or a placebo infusion and performed coagulation tests in the preoperative and postoperative periods.

\section{Methods}

The study was a prospective, double-blind, randomized trial (randomization was done by Toronto General Hos- pital, Research Division, Pharmacy). Approval for the study was received from our institution's ethics review board and informed consent was obtained from all patients.

One hundred fifty patients scheduled to undergo cardiac operations with CPB were randomized into three groups of equal size. The first group, designated TA-10, received an infusion of $10 \mathrm{gm}$ of TA intravenously over 20 minutes after induction of anesthesia and a placebo infusion over the subsequent 5 hours. The second group, TA-20, received $10 \mathrm{gm}$ of TA over 20 minutes and then a further $10 \mathrm{gm}$ infused intravenously over 5 hours. The third group, a control group, received a placebo bolus and a placebo infusion over 5 hours $(0.9 \%$ normal saline solution). All patients were stratified to either a high- or low-risk category with respect to bleeding and patients in these categories were equally distributed among the three groups. Patients at high risk were defined as those patients who had undergone previous cardiac operations with $\mathrm{CPB}$, patients undergoing operation on more than one heart valve, patients undergoing aortacoronary bypass and operation on a heart valve, and patients undergoing operation because of septic endocarditis. All patients received high-dose fentanyl anesthesia, 50 to $75 \mu \mathrm{g} / \mathrm{kg}$, pancuronium $0.15 \mathrm{mg} / \mathrm{kg}$, and diazepam 0.1 to $0.2 \mathrm{mg} / \mathrm{kg}$. Heparin ( 300 units $/ \mathrm{kg}$ ) was given intravenously to achieve an activated clotting time of more than 400 seconds before $\mathrm{CPB}$. Additional heparin was added throughout CPB to maintain activated clotting time at more than 400 seconds. After CPB, the effect of heparin was neutralized by administration of protamine sulfate $(1 \mathrm{mg} / 100$ units heparin) to achieve an activated clotting time $\pm 10 \%$ of baseline values.

The cardiac pump was primed with $2 \mathrm{~L}$ Ringer's lactate, $100 \mathrm{ml} 25 \%$ albumin, $50 \mathrm{mEq}$ sodium bicarbonate, and $100 \mathrm{ml} 20 \%$ mannitol. A membrane oxygenator (Maxima, Medtronic, Inc., Minneapolis, Minn.) was used for all patients.

The blood from the CPB circuit was salvaged and transfused to the patient at the end of the operation. The volume and hematocrit concentration of the blood that was suctioned from the operating site, excluding CPB, were measured and the number of grams of hemoglobin lost intraoperatively was calculated.

After operation, blood loss from two mediastinal drains was collected in a sterile cardiotomy reservoir and autotransfused to the patient when drainage exceeded $150 \mathrm{ml}$ for the first 6 hours. Total blood loss was measured at 6 and 24 hours.

Homologous blood and blood products given during the operation and up to 48 hours after the operation were recorded.

Hematologic and coagulation tests. Complete blood cell counts, including platelet counts, were done with a TOA electronic blood cell counter (Baxter Industries, Toronto, Ontario, Canada) and checked for accuracy with a microscopic examination of a fixed, stained film.

The bleeding times were determined with a bleeding time device (Template II, Organon-Teknika, Akzo, Pharma Group, Scarborough, Ontario, Canada).

The prothrombin times and activated partial thromboplastin times were determined with standard commercial 
reagents (Thromborel-S, Hoechst-Roussel, Montreal, Quebec, Canada; Platelin-LS, Organon-Teknika) in an automatic coagulation device (Automated Coagulation Laboratory, ACL, Coulter Electronics of Canada, Burlington, Ontario, Canada).

The activity of plasminogen and $\alpha_{2}$-antiplasmin were determined by means of a chromogenic substrate specific for each activity (Kabi-Pharmacia Laboratories, Toronto, Ontario, Canada).

The fibrinogen level was determined by the Clauss method.

D-dimer values were determined by the latex agglutination slide method with a commercial kit (Bio Pool, Burlington, Ontario, Canada).

These tests were done before, during, and after the operation.

Blood product administration. Patients were given red blood cells (RBCs) if the hematocrit value was $19 \%$ or less during CPB or less than $20 \%$ on two consecutive measurements during intensive care unit (ICU) care after operation. Platelets, fresh frozen plasma, and cryoprecipitate were given at the discretion of a single hematologist who was blinded to the study. Platelets ( 5 units) were given to the patient if the platelet count was less than $50 \times$ $10^{9} \mathrm{~L}^{-1}$. Cryoprecipitate (4 units) or fresh frozen plasma ( 1 unit) were given to patients if the prothrombin time was greater than 1.5 times normal value. Protamine sulfate, 25 to $50 \mathrm{mg}$ diluted in $50 \mathrm{ml}$ of normal saline solution and infused over 30 minutes, was given in the ICU if the activated clotting time exceeded the baseline value for that patient by more than $10 \%$.

Patients who shed more than $200 \mathrm{ml}$ blood per hour in 2 consecutive hours or $400 \mathrm{ml}$ in 1 hour were treated with $\epsilon$-aminocaproilc acid 15 to $30 \mathrm{mg}$ over 24 hours. The choice of $\epsilon$-aminocaproic acid for use in treating bleeding after operation was dictated by logistics because it was available in the ICU and was the previous standard treatment for bleeding after operation. Some patients who had excessive bleeding received desmopressin $0.4 \mu \mathrm{g} / \mathrm{kg}$ diluted in $50 \mathrm{ml}$ of normal saline solution and infused intravenously over 30 minutes.

Statistics. Sample size calculation was done with an assumption of a mean value difference among the groups of $200 \mathrm{ml}$ blood loss with standard deviation of $200 \mathrm{ml}$ and alpha of 0.05 and beta of $80 \%$.

Blood loss volumes (in milliliters) at 6 and 24 hours were logarithmically transformed. Mean values of the blood loss in the three groups were compared by one- and two-way analysis of variance. When $p=0.05$, multiple post-hoc comparisons were done (Tukey tests). Confidence intervalls at $95 \%$ (CI.95) were calculated on logarithmically transformed values. Mean values and confidence intervals were then antilogarithmically transformed to milliliters of blood. Blood and blood products transfused were analyzed as a proportion of patients receiving them per group. CI.95 values were calculated for each proportion, and $\chi^{2}$ tests were used to compare frequencies. Continuous measurements were compared with analysis of variance for within- and between-group effects. Data are presented as mean plus or minus the standard error of the mean, percent value, or number count.
Table I. Demographic data and surgical characteristics

\begin{tabular}{|c|c|c|c|}
\hline & \multicolumn{3}{|c|}{ Group } \\
\hline & $\begin{array}{c}T A-10 \\
(N=49)\end{array}$ & $\begin{array}{c}T A-20 \\
(N=50)\end{array}$ & $\begin{array}{c}\text { Control } \\
(N=48)\end{array}$ \\
\hline Age (yr) & $59 \pm 3$ & $63 \pm 1$ & $58 \pm 2$ \\
\hline Weight (kg) & $79 \pm 2$ & $80 \pm 2$ & $80 \pm 2$ \\
\hline $\begin{array}{l}\text { Hb preoperative } \\
(\mathrm{gm} / \mathrm{L})\end{array}$ & $142 \pm 2$ & $144 \pm 2$ & $149 \pm 2^{*}$ \\
\hline $\begin{array}{l}\mathrm{Hb} \text { postoperative } \\
\quad(\mathrm{gm} / \mathrm{L})\end{array}$ & $103 \pm 2$ & $103 \pm 2$ & $112 \pm 3$ \\
\hline Bypass time (min) & $99 \pm 5$ & $99 \pm 5$ & $93 \pm 5$ \\
\hline $\begin{array}{l}\text { Lowest temperature } \\
\text { on bypass }\left({ }^{\circ} \mathrm{C}\right)\end{array}$ & $30.6 \pm 0.4$ & $30.0 \pm 0.3$ & $31.0 \pm 0.4$ \\
\hline No. of valve operations & 14 & 10 & 8 \\
\hline No. of CABG operations & 33 & 37 & 35 \\
\hline $\begin{array}{l}\text { No. of valve } \\
\quad+\text { CABG operations }\end{array}$ & 2 & 3 & 5 \\
\hline $\begin{array}{l}\text { No. of operations } \\
\text { involving LIMA }\end{array}$ & 29 & 30 & 35 \\
\hline $\begin{array}{l}\text { No. of patients } \\
\text { receiving ASA }\end{array}$ & 31 & 32 & 34 \\
\hline $\begin{array}{l}\text { No. of patients with high- } \\
\text { risk conditions }\end{array}$ & 28 & 27 & 30 \\
\hline No. of reoperations & 6 & 12 & 11 \\
\hline
\end{tabular}

High risk for increased bleeding is defined as patients undergoing reoperation, valve operation and coronary bypass, multiple valve procedures, or operation for septic endocarditis. Data are given as mean plus or minus standard error of the mean or number count. No statistically significant differences per treatment group were present, except preoperative hemoglobin level. $H b$, Hemoglobin; $C A B G$, coronary artery bypass grafting; $L I M A$, left internal manımary artery; $A S A$, acetylsalicylic acid.

$* p=0.05$.

Statistical analysis was done with the SYSTAT program, version 5.0 (Systat Inc., Evanston, Ill.).

Three patients who underwent reoperation to control surgical bleeding were excluded from the statistical analysis.

\section{Results}

Demographic data and surgical characteristics are presented in Table I. Hemoglobin concentration before the operation was significantly higher in the control group than in the treatment groups $(p=$ 0.05 ).

The number of patients who had excessive bleeding in the postoperative period is presented in Table II. A total of 11 patients had excessive bleeding during the early postoperative period $(>750 \mathrm{ml}$ in the first 6 postoperative hours). Nine patients (18\%) in the control group had excessive bleeding; however, only one patient in the TA-10 group and one in the TA-20 group ( $2 \%, p=0.001)$ had excessive bleeding.

The patients who had excessive bleeding lost $184 \%$ more blood during the initial 6 hours $(p=$ 
Table II. Excessive postoperative bleeding

\begin{tabular}{ccc}
\hline Group & $\begin{array}{c}6 \text { hr blood loss } \\
>750 \mathrm{ml}\end{array}$ & $\begin{array}{c}6 \mathrm{hr} \text { blood loss } \\
<750 \mathrm{ml}\end{array}$ \\
\hline TA-10 & 1 & 48 \\
TA-20 & 1 & 49 \\
Control & $9^{*}$ & 39 \\
${ }^{*} p=0.001$. &
\end{tabular}

0.0001 ) and $77 \%$ more blood during the initial 24 hours after operation than the remainder of the patients. Those patients who had excessive bleeding required an increased volume of autotransfusion $(250 \%, p=0.0001)$ and $\mathrm{RBC}$ transfusion $(93 \%, p=$

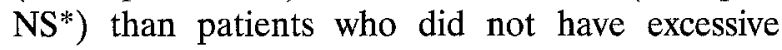
bleeding (Fig. 1). Eight patients who had excessive bleeding received $\epsilon$-aminocaproic acid (10 to $40 \mathrm{gm}$ ) after operation. Only four patients in the group without excessive bleeding received $\epsilon$-aminocaproic acid (10 to $30 \mathrm{gm})$. There was no significant difference in demographics between those patients who had excessive bleeding and those who did not.

Amounts of blood loss in the TA-10, TA-20, and control groups during the first 24 hours after operation are presented in Fig. 2. During the first 6 hours after operation, there was a significant reduction in blood loss in both treatment groups (TA-10 group had a $50 \%$ reduction and TA-20 group had a 53\% reduction) compared with blood loss in the control group ( $p=0.0001)$. There was no significant difference with respect to blood loss between the treatment groups, TA-10 and TA-20, during the first 6 hours.

Amounts of blood loss from 6 to 24 hours are presented in Fig. 2. During this 18 -hour period, only the TA-20 group had significantly less bleeding than the control group $(p=0.03)$ with a $21 \%$ decrease in the blood loss. The TA-10 group had only an 18\% decrease in blood loss compared with that in the control group, which is not statistically significant.

Overall, during the first 24 hours after operation, there was a significant reduction in postoperative blood loss in both treatment groups (TA-10 group had a $35 \%$ and TA-20 group had a $37 \%$ reduction in blood loss) compared with that in the control group $(p=0.0001)$. There was no significant difference with respect to blood loss between the treatment groups over 24 hours.

Intraoperative blood loss expressed as grams of hemoglobin did not differ between treatment and nontreatment groups; however, patients at high risk

${ }^{*} \mathrm{NS}=$ Not significant. for bleeding lost significantly more hemoglobin intraoperatively $(52 \pm 35 \mathrm{gm})$ than patients at low risk $(34 \pm 22 \mathrm{gm})(p=0.001)$.

There was no significant difference in transfusions of RBCs, platelets, cryoprecipitate, and fresh frozen plasma between treatment and control groups. Forty percent of patients received RBCs (mean 2 units per patient receiving transfusion), only three patients received cryoprecipitate, and three patients received platelet concentrate. The strongest predictor of the need for RBC transfusion was the preoperative hemoglobin level $(p=0.007$ by univariate analysis).

Autotransfusion was undertaken if the patient had greater than $150 \mathrm{ml}$ blood loss in the first 6 hours. Significantly fewer patients in the two treatment groups, TA-10 (27\%, CI.95 39 to 15) and TA-20 (44\%, CI.95 58 to 30$)$, received an autotransfusion in comparison with the respective number in the control group (83\%, CI.95 94 to $69, p=0.001$ ). Likewise, the volume of blood autotransfused was less in the treatment groups (TA-10, 44\%; TA-20, $52 \%$ ) than in the control group.

Results of coagulation tests. Results of the coagulation tests before and after operation did not differ among the three groups. To assess the differences in coagulation systems between patients with and without excessive bleeding we analyzed the data of the 9 patients from the control group who had excessive bleeding and compared these results with those of 20 patients randomly selected from the control group who did not have excessive bleeding. Results of this comparison are presented in Tables III and IV. Results of coagulation tests done before operation did not differ among these two groups. However, results of the coagulation tests were different between the two groups when done during and immediately after operation. Fibrinogen level was significantly lower after CPB in patients who had excessive bleeding. Plasminogen activity and $\alpha_{2}$-antiplasmin levels were significantly lower on arrival in the ICU in patients who had excessive bleeding. The plasminogen activity was still significantly lower 24 hours after CPB in patients with excessive bleeding. These patients with excessive bleeding had significantly prolonged bleeding times, prothrombin times, and activated partial thromboplastin times in the immediate postoperative period.

Complications. No patient had a perioperative myocardial infarction as indicated by electrocardiographic changes and plasma concentrations of cardiac enzymes. A total of three patients had a stroke 


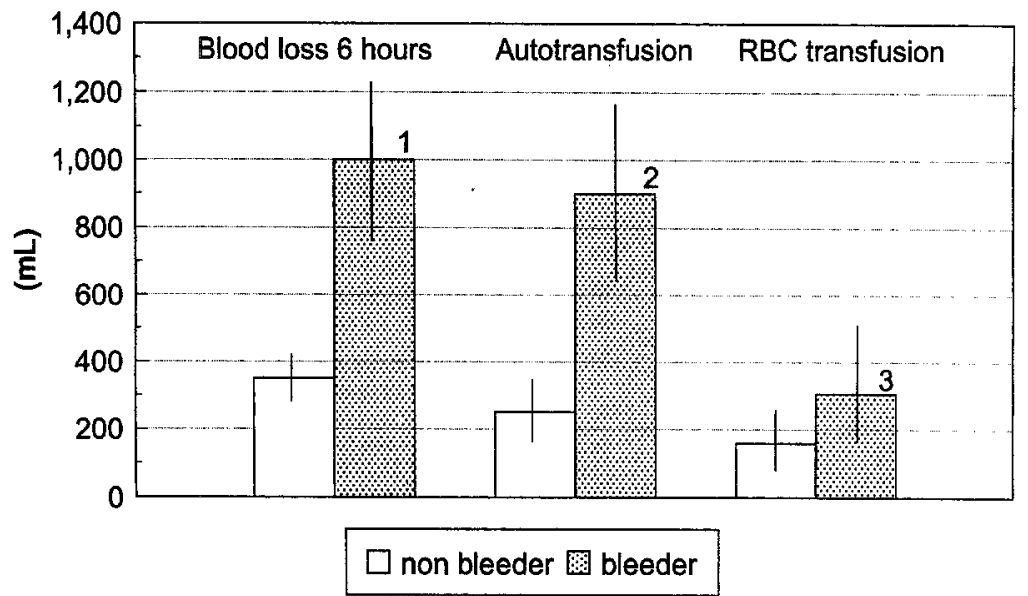

Fig. 1. Blood loss, autotransfusion, and RBC transfusion compared between patients with and without excessive bleeding. Patients with excessive bleeding lost significantly more blood and received significantly more autotransfusion and RBC transfusion than patients without excessive bleeding. Bleeder, Patients with more than $750 \mathrm{ml}$ blood loss in first 6 postoperative hours; non bleeder, patients with less than $750 \mathrm{ml}$ blood loss in first 6 postoperative hours ( 20 patients randomly selected from control).

${ }^{1}$ Patients who had excessive bleeding lost $184 \%$ more blood during initial 6 hours $(p=0.0001)$.

${ }^{2}$ Patients who had excessive bleeding required increased volume of autotransfusion $(250 \%, p=0.0001)$.

${ }^{3}$ Patients who had excessive bleeding received increased volume of RBC transfusion $(93 \%, p=\mathrm{NS})$.

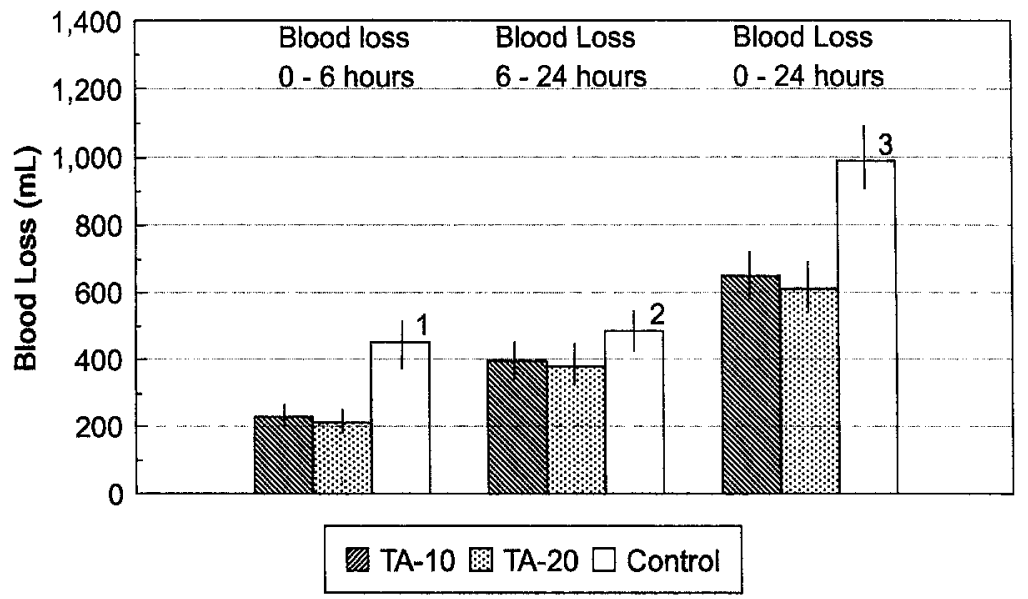

Fig. 2. Blood loss during periods from 0 to 6 hours, 6 to 24 hours, and 0 to 24 hours after operation. ${ }^{1}$ Blood loss from 0 to 6 hours is reduced by 50\% in TA-10 group and 53\% in TA-20 group compared with that in control group $(p=0.0001)$. There was no difference in blood loss between TA-10 and TA-20 groups. ${ }^{2}$ Blood loss from 6 to 24 hours was reduced by $21 \%$ in TA-20 group compared with that in control group $(p=0.03)$. Blood loss in TA-10 group was not statistically significant when compared with that in control group. ${ }^{3}$ Total blood loss during first 24 hours after operation was reduced by $35 \%$ in TA-10 group and $37 \%$ in TA-20 group compared with that in control group $(p=0.0001)$. There was no difference in blood loss between TA-10 and TA-20 groups.

after operation. Two of these patients were in the TA-10 group, one in the TA-20 group, and none in the control group ( $p=\mathrm{NS}$ ). All three patients had advanced widespread peripheral vascular disease and two had had previous strokes.

\section{Discussion}

The most important conclusion of this study is that a single $10 \mathrm{gm}$ dose of TA given intravenously before sternotomy reduces the percentage of patients who have excessive bleeding (more than 750 
Table III. Hemotologic and coagulation findings

\begin{tabular}{|c|c|c|c|}
\hline Group & $P T(\mathrm{sec})$ & $\operatorname{aPTT}(\mathrm{sec})$ & Bleeding time (min) \\
\hline Normal range & $9.8-12$ & $25-38$ & $<6$ \\
\hline \multicolumn{4}{|l|}{ Before operation } \\
\hline Patients with excessive bleeding & $11.3 \pm 0.3$ & $31.7 \pm 2.4$ & $4.7 \pm 0.5$ \\
\hline Patients without excessive bleeding & $11.2 \pm 0.5$ & $28.3 \pm 1.1$ & $4.1 \pm 0.4$ \\
\hline$p$ Value & NS & NS & NS \\
\hline \multicolumn{4}{|l|}{ After operation } \\
\hline Patients with excessive bleeding & $17.0 \pm 0.5$ & $39.7 \pm 2.4$ & $11.0 \pm 1.2$ \\
\hline Patients without excessive bleeding & $15.0 \pm 0.4$ & $32.8 \pm 1.0$ & $6.5 \pm 1.2$ \\
\hline$p$ Value & 0.006 & 0.004 & 0.03 \\
\hline \multicolumn{4}{|l|}{$4 \mathrm{hr}$ post-CPB } \\
\hline Patients with excessive bleeding & $13.7 \pm 0.7$ & $30.3 \pm 3.4$ & NA \\
\hline Patients without excessive bleeding & $13.7 \pm 0.6$ & $28.9 \pm 1.5$ & NA \\
\hline$p$ Value & NS & NS & NA \\
\hline \multicolumn{4}{|l|}{$12 \mathrm{hr}$ post-CPB } \\
\hline Patients with excessive bleeding & $14.7 \pm 0.4$ & $36.8 \pm 2.9$ & $7.6 \pm 1.2$ \\
\hline Patients without excessive bleeding & $13.6 \pm 0.3$ & $31.7 \pm 1.3$ & $4.7 \pm 0.4$ \\
\hline$p$ Value & 0.03 & NS & 0.01 \\
\hline
\end{tabular}

Comparison of the coagulation profile between 9 patients with excessive bleeding from the control group and 20 patients without excessive bleeding from the control group. Patients with excessive bleeding shed more than $750 \mathrm{ml}$ blood in the first 6 postoperative hours; patients without excessive bleeding shed less than $750 \mathrm{ml}$ blood in the first 6 postoperative hours. Data are given as mean plus or minus standard error of the mean. PT, Prothrombin time; aPTT, activated partial thromboplastin time; $N S$, not significant; $N A$, not available.

Table IV. Hemotologic and coagulation findings

\begin{tabular}{|c|c|c|c|c|c|c|}
\hline Group & $\begin{array}{c}\text { Plasminogen } \\
\text { activity } \\
\text { (units/ml) }\end{array}$ & $\begin{array}{c}\text { Fibrinogen } \\
\text { level } \\
(\mathrm{gm} / \mathrm{L})\end{array}$ & $\begin{array}{c}\text { D-dimers } \\
(\mathrm{ng} / \mathrm{ml})\end{array}$ & $\begin{array}{c}\alpha_{2} \text {-Antiplasmin } \\
\text { activity } \\
\text { (units } / m l)\end{array}$ & $\begin{array}{c}\text { Platelets } \\
\text { (billion } / L)\end{array}$ & $\begin{array}{c}\text { Hematocrit } \\
(L / L)\end{array}$ \\
\hline Normal range & $0.8-1.2$ & $1.5-3.5$ & $<500$ & $0.8-1.2$ & $150-400$ & $0.40-0.54$ \\
\hline \multicolumn{7}{|l|}{ Before operation } \\
\hline Patients with excessive bleeding & $0.95 \pm 0.02$ & $3.3 \pm 0.2$ & $394 \pm 52$ & $1.09 \pm 0.05$ & $249 \pm 10$ & $0.43 \pm 0.03$ \\
\hline Patients without excessive bleeding & $0.95 \pm 0.04$ & $3.4 \pm 0.2$ & $373 \pm 43$ & $1.01 \pm 0.03$ & $224 \pm 16$ & $0.43 \pm 0.01$ \\
\hline$p$ Value & NS & NS & NS & NS & NS & NS \\
\hline \multicolumn{7}{|l|}{ After sternotomy } \\
\hline Patients with excessive bleeding & $0.89 \pm 0.05$ & $2.8 \pm 0.2$ & $350 \pm 48$ & $0.94 \pm 0.05$ & $209 \pm 7$ & $0.38 \pm 0.01$ \\
\hline Patients without excessive bleeding & $0.87 \pm 0.03$ & $3.5 \pm 0.2$ & $367 \pm 44$ & $0.93 \pm 0.03$ & $179 \pm 9$ & $0.37 \pm 0.01$ \\
\hline$p$ Value & NS & 0.06 & NS & NS & 0.05 & NS \\
\hline \multicolumn{7}{|l|}{ End of CPB } \\
\hline Patients with excessive bleeding & $0.48 \pm 0.04$ & $1.4 \pm 0.1$ & $408 \pm 38$ & NA & $158 \pm 10$ & $0.23 \pm 0.01$ \\
\hline Patients without excessive bleeding & $0.53 \pm 0.02$ & $2.0 \pm 0.2$ & $366 \pm 34$ & NA & $148 \pm 11$ & $0.25 \pm 0.01$ \\
\hline$p$ Value & NS & 0.02 & NS & NA & NS & 0.01 \\
\hline \multicolumn{7}{|l|}{ ICU } \\
\hline Patients with excessive bleeding & $0.43 \pm 0.05$ & $1.3 \pm 0.2$ & $746 \pm 186$ & $0.52 \pm 0.03$ & $107 \pm 7$ & $0.23 \pm 0.01$ \\
\hline Patients without excessive bleeding & $0.62 \pm 0.03$ & $2.3 \pm 0.2$ & $839 \pm 176$ & $0.69 \pm 0.04$ & $130 \pm 10$ & $0.27 \pm 0.01$ \\
\hline$p$ Value & 0.003 & 0.008 & NS & 0.007 & NS & 0.02 \\
\hline \multicolumn{7}{|l|}{$24 \mathrm{hr}$ post-CPB } \\
\hline Patients with excessive bleeding & $0.41 \pm 0.04$ & $2.9 \pm 0.4$ & $513 \pm 82$ & NA & $114 \pm 8$ & $0.25 \pm 0.01$ \\
\hline Patients without excessive bleeding & $0.69 \pm 0.04$ & $3.8 \pm 0.3$ & $630 \pm 194$ & NA & $130 \pm 11$ & $0.27 \pm 0.01$ \\
\hline$p$ Value & 0.0001 & NS & NS & NA & NS & NS \\
\hline
\end{tabular}

Comparison of the coagulation profile between nine patients with excessive bleeding from the control group and 20 patients without excessive bleeding from the control group. Patients with excessive bleeding shed more than $750 \mathrm{ml}$ blood in the first 6 postoperative hours; patients without excessive bleeding shed less than $750 \mathrm{ml}$ blood in the first 6 postoperative hours. Data are given as mean plus or minus standard error of the mean. NS, Not significant; $N A$, not available.

$\mathrm{ml}$ in 6 hours) after $\mathrm{CPB}$ from $18 \%$ to $2 \%$. In addition, $10 \mathrm{gm}$ of TA reduces blood loss in the postoperative period by $50 \%$ during the first 6 hours and by $35 \%$ during the first 24 hours after operation in comparison with the use of placebo. An additional $10 \mathrm{gm}$ of TA ( $20 \mathrm{gm}$ in total) in a subsequent 5-hour infusion did not improve blood preservation after operation. These findings confirm our previous 
results and indicate that pretreatment with the antifibrinolytic agent TA $(10 \mathrm{gm})$ before CPB prevents excessive postoperative blood loss and reduces the need for blood transfusion. The reduced need for RBC transfusion (93\%) was evident when patients with and without excessive bleeding were compared. The difference in RBC transfusion between these groups was not statistically significant probably because of the small number of patients being compared ( 9 with and 20 without bleeding). Overall, there was no difference in the RBC transfusion requirement between the treatment and control groups. The control group had a significantly higher preoperative hemoglobin level, and, in addition, patients from the control group who had excessive bleeding received autotransfusion and were treated with antifibrinolytic drugs for ethical reasons. Autotransfusion and drug treatment reduced blood loss and the need for RBC transfusion within the control group.

Results from coagulation tests done during this study indicate that there are no differences in coagulation parameters before operation between patients with and without excessive bleeding. Thus it is impossible to predict with the use of standard coagulation tests who will have excessive bleeding after heart operations done with CPB. Results from coagulation tests done after operation clearly indicate that patients with excessive bleeding had ongoing coagulopathy (increased fibrinolysis and platelet dysfunction) on arrival at the ICU. These changes in the coagulation system, which started immediately after sternotomy, persisted for up to 24 hours after operation. Similar changes in coagulation parameters were observed in two patients from the TA groups with excessive bleeding. The most probable causes of excessive bleeding were increased fibrinolysis (decreased plasminogen activity and decreased $\alpha_{2}$-antiplasmin activity) and abnormal platelet function (prolonged bleeding time) seen after the operation. We assume that by giving the antifibrinolytic agent TA before operation we were able to prevent fibrinolysis and protect platelets, which, as indicated by Huang and co-workers ${ }^{8}$ and Soslau, Horrow, and Brodsky, ${ }^{9}$ eliminated excessive bleeding in the postoperative period.

The exact mechanism of induction of fibrinolysis by CPB is not clear. It is thought that fibrinolysis during cardiac operations with CPB is likely elicited physiologically by thrombin generation and fibrin production. Plasmin generated during activation of fibrinolysis has a damaging effect on platelet func- tion. It is postulated by $\mathrm{Lu}$ and associates ${ }^{24}$ that a low concentration of plasmin $\left(0.1\right.$ to $\left.1.0 \mathrm{CU}^{*} / \mathrm{ml}\right)$ inhibits platelet activation by thrombin or collagen and that a high concentration of plasmin $(>1.5$ $\mathrm{CU} / \mathrm{ml}$ ) activates platelets.

With respect to the type of platelet damage induced by fibrinolysis and plasmin formation, two recent papers suggested that platelet receptors are differentially redistributed by the effect of plas$\min .{ }^{25,}{ }^{26}$ Plasmin treatment of the platelets at normothermia resulted in the disappearance of platelet glycoprotein Ib from the cell surface and its subsequent redistribution into the channels and vesicles of the surface-connected canalicular system with significantly modified glycoprotein IIb/IIIa remaining on the plasma membrane. Disappearance of the glycoprotein $\mathrm{Ib}$ from the platelet surface prevents effective binding of the platelets to von Willebrand's factor and inhibits initiation of clotting. These results were not supported by the findings of Kestin and associates ${ }^{10}$ in which the authors concluded that CPB results in markedly deficient platelet reactivity in response to the in vivo wound in which platelet surface glycoproteins $\mathrm{Ib}$ and IIb/IIIa are preserved. They concluded that platelet dysfunction after CPB is not a defect intrinsic to the platelets, but rather an extrinsic defect such as in vivo lack of availability of platelet agonists. Although there is not a consensus as to the nature of damage inflicted on platelets by CPB the end point remains the same: excessive blood loss after operation.

We have seen excessive bleeding in $18 \%$ of patients undergoing CPB who have not received TA before operation, and it will remain unknown for some time why only these patients had excessive bleeding. Future research should be directed toward the preoperative diagnosis of the risk for excessive postoperative blood loss. Subsequently, only those patients who are at risk should be pretreated with antifibrinolytic drugs before CPB, which will reduce expense and limit the exposure to antifibrinolytic agents. Until that time, the best way to protect patients from excessive blood loss after cardiac operation is to pretreat all patients with an antifibrinolytic agent before operation thereby preventing plasmin formation and subsequent damage to platelets.

We express our appreciation for the contribution of the cardiac surgeons of The Toronto Hospital and Dr. Eric Yeo, staff hematologist, for his help in interpreting the hematologic and coagulation data.

${ }^{*} \mathrm{CU}=$ Caseinolytic unit. 
REFERENCES

1. Talamonti MS, LoCicero J III, Hoyne WP, et al. Early re-exploration for excessive postoperative bleeding lowers wound complication rates in open heart surgery. Am Surg 1987;53:102-4.

2. Mori F, Nakahara Y, Kurata S, et al. Late changes in haemostatic parameters following open heart surgery. J Cardiovasc Surg 1982;23:458-62.

3. Bagge L, Lilienberg G, Nystrom SO, Tyden H. Coagulation, fibrinolysis and bleeding after open-heart surgery. Scand J Thorac Cardiovasc Surg 1986;20:15160.

4. Bick RL. Hemostatic defects associated with cardiac surgery, prosthetic devices, and extracorporeal circuits. Semin Thromb Hemost 1985;11:249-80.

5. Holloway DS, Summaria L, Sandesara J, et al. Decreased platelet number and function and increased fibrinolysis contribute to postoperative bleeding in cardiopulmonary bypass patients. Thromb Haemost 1988;59:62-7.

6. Kucuk O, Kwaan HC, Frederickson J, et al. Increased fibrinolytic activity in patients undergoing cardiopulmonary bypass operation. Am J Hematol 1986;23: 223-9.

7. Verstraete M. Clinical application of inhibitors of fibrinolysis. Drugs 1985;29:236-61.

8. Huang H, Ding W, Su Z, Zhang W. Mechanism of the preserving effect of aprotinin on platelet function and its use in cardiac surgery. J THORAC CARDIOVASC SuRG 1993;106:11-8.

9. Soslau G, Horrow J, Brodsky I. Effect of tranexamic acid on platelet ADP during extracorporeal circulation. Am J Hemat 1991;38:113-9.

10. Kestin AS, Valeri R, Khuri SF, et al. The platelet function defect of cardiopulmonary bypass. Blood 1993;82:107-17.

11. Lambert CJ, Marengo-Rowe AJ, Leveson JE, et al. The treatment of postperfusion bleeding using $\epsilon$-aminocaproic acid, cryoprecipitate, fresh-frozen plasma, and protamine sulfate. Ann Thorac Surg 1979;28: 440-5.

12. McNicol GP, Fletcher AP, Alkjaesig N, Sherry S. The absorption, distribution, and excretion of $\epsilon$-aminocaproic acid following oral and intravenous administration in man. J Lab Clin Med 1962;59:15-24.

13. Hoylaerts M, Lijnen HR, Collen D. Studies on the mechanism of antifibrinolytic action of tranexamic acid. Biochim Biophys Acta 1981;673:75-85.

14. Pilbrant A, Schannong M, Vessman J. Pharmacoki- netics and bioavailability of tranexamic acid. Eur $\mathbf{J}$ Clin Phamacol 1981;20:65-72.

15. Thorsen S. Differences in the binding to fibrin of native plasminogen and plasminogen modified by proteolytic degradation: influence of omega aminocarboxylic acids. Biochim Biophys Acta 1975;393:5565.

16. Eriksson O, Kjellman H, Pilbrant A, Schannong M. Pharmacokinetics of tranexamic acid after intravenous administration to normal volunteers. Eur J Clin Pharmacol 1974;7:375-80.

17. Markwardt F, Nowak G, Meerbah W, Rudiger KS. The influence of drugs on disseminated intravascular coagulation (DIC): effects of antifibrinolytics and fibrinolytics on thrombin-induced DIC in rats. Thromb Res 1976;9:143-52.

18. DelRossi AJ, Cernaianu AC, Botros S, et al. Prophylactic treatment of postperfusion bleeding using EACA. Chest 1989;96:27-30.

19. Vander Salm TJ, Ansell JE, Okike ON, et al. The role of $\epsilon$-aminocaproic acid in reducing bleeding after cardiac operation: a double-blind randomized study. J Thorac Cardiovasc Surg 1988;95:538-40.

20. Sterns LP, Lillehei CW. Effect of $\epsilon$-aminocaproic acid upon blood loss following open-heart surgery: an analysis of 340 patients. Can J Surg 1967;10:30497.

21. Horrow JC, Hlavacek J, Strong MD, et al. Prophylactic tranexamic acid decreases bleeding after cardiac operations. J THORAC Cardiovasc SURG 1990;99: 70-4.

22. Horrow JC, Van Riper DF, Strong MD, et al. Hemostatic effects of tranexamic acid and desmopressin during cardiac surgery. Circulation 1991;85:2063-70.

23. Karski JM, Teasdale SJ, Norman P, et al. Prevention of post bypass bleeding with tranexamic acid and e-aminocaproic acid. J Cardiothorac Vasc Anesth 1993; 7:431-5.

24. Lu H, Soria C, Crammer EM, et al. Temperature dependence of plasmin-induced activation or inhibition of human platelets. Blood 1991;77:996-1005.

25. Cramer EM, Lu H, Caen J, et al. Differential redistribution of platelet glycoproteins Ib and IIb-IIIa after plasmin stimulation. Blood 1991;77:694-9.

26. Lu H, Soria C, Soria J, et al. Reversible translocation of glycoprotein Ib in plasmin-treated platelets: consequences for platelet function. Eur J Clin Invest 1993; 23:785-93. 